\title{
EL PESIMISMO ANTROPOLÓGICO Y LA FUNDAMENTACIÓN DE LA TEORÍA DEL ESTADO EN HOBBES Y SCHMITT
}

CRISTINA MICIELI

UBA-UNGSM

\section{"La naturaleza humana es egoísmo"}

¿Cómo se propone Hobbes elaborar un cuerpo de normas irrefutables, apodícticas, conforme a las cuales una sociedad tiene que organizarse para adquirir seguridad?

Una única ciencia nos $\mathrm{da}$, en opinión de Hobbes, un conocimiento cierto y apodíctico, ya que con su método podemos descubrir las verdaderas causas de las cosas. Se trata de la geometría -en términos generales de la matemática-, única ciencia que "Dios comunicó al género humano"1.

Por lo tanto, para alcanzar el resultado que Hobbes se propone será necesario aplicar en la construcción y mantenimiento de los Estados, normas tan ciertas y seguras como las de la geometría y la aritmética. Sólo si es posible hacer esto, es decir, "construir geométricamente los Estados", se logrará superar la situación de crisis pre-política que atraviesan los individuos en el estado de naturaleza.

Para Hobbes, Galileo pudo descubrir las verdaderas causas de las cosas, que hasta entonces habían permanecido ocultas para los hombres, porque encontró la manera de aplicar la geometría al análisis de los fenómenos naturales, reduciendo la realidad de la naturaleza a cuerpo y movimiento. Con esta reducción, Galileo pudo aplicar la geometría a la realidad natural porque movimiento son susceptibles de medida, esto es, son cuantificables.

Hobbes planteará, a su vez, que no sólo la naturaleza es reducible a cuerpo y movimiento en su verdadero ser, sino que la realidad psíquica y la realidad social también lo son. Todo tipo de realidad -la realidad corpórea, natural, psicológica, social o política- es reducible a un solo tipo de ser corpóreo y mecánico. En consecuencia, la sociedad y el Estado son un cuerpo, y todo lo que ocurre en ellos es explicable en términos de

\footnotetext{
${ }^{1}$ Hobbes, Thomas, Leviatán, Parte I, cap. 4, Ed. UPR, Puerto Rico, 1978, p. 37.
} 
movimiento, del mismo tipo que hallamos en el ámbito de la realidad natural. Como vemos, el supuesto fundamental de Hobbes es la afirmación metafísica de un monismo materialista: la afirmación de que todo el ser se reduce a cuerpo y movimiento.

A partir de este monismo, el filósofo considera haber resuelto todos los problemas que le antecedieron para elaborar una teoría política apodíctica, teoría que va a desarrollar fundamentalmente en el Leviatan ${ }^{2}$, su máxima obra.

Con este punto de partida, comienza su análisis de la realidad humana utilizando el movimiento como principio explicativo, y sigue una secuencia lógico-deductiva. En efecto, dos clases de movimientos son constitutivos de los seres vivos: los vitales, como la circulación de la sangre, el pulso, la respiración, la nutrición, etc., y los voluntarios -andar, hablar, entre otros. Los movimientos voluntarios, por su parte, en la medida en que se dirigen hacia algo que los causa, se llaman apetitos o deseos, y cuando se apartan de lo que los rechaza reciben el nombre de aversión. Aquello que los hombres apetecen o desean, dicen que lo aman; lo que les provoca aversión, lo odian. Lo que es deseado es bueno, provocando como sensación el placer, mientras que lo que es odiado es malo y la sensación que provoca es el desagrado.

Asimismo, apetito, amor, aversión, odio, placer, desagrado son las pasiones más simples, a partir de las cuales se originan todas las otras, ya que por medio de la combinación de los elementos simples surgen los más complejos. La identificación de lo bueno con el placer, en consecuencia, es el fundamento de la concepción ética hedonista de Hobbes.

Los movimientos voluntarios, por su parte, tienen como única finalidad mantener, proteger y asegurar los movimientos vitales. En este sentido, el motor de toda conducta es conservar o aumentar la vitalidad del cuerpo vivo; no hay otro móvil de los movimientos voluntarios fuera de éste. Es decir que el principio de toda conducta, su móvil exclusivo, es el principio de la propia conservación biológica, por lo cual es bueno lo que favorece y asegura esa conservación, y malo lo que la perjudica. Cualquier otro móvil no será más que la combinación de las pasiones simples y de

${ }^{2}$ Leviatán es una alusión bíblica que hace referencia a un monstruo que aparece en el Libro de Job, 40; con ella Hobbes designa al Estado, con lo cual el autor expresa que el Estado es un mal, aunque un mal menor frente a lo que significa la falta de un Estado. 
otros elementos para enmascarar, de alguna manera, este motor fundamental que es el de la conservación de la vida.

Principio fundamental de la antropología de Hobbes, el hedonismo individual es el principio básico que explica los movimientos de la conducta humana. Así, por ejemplo, la felicidad no es otra cosa que el aumento continuo de los medios que nos permiten satisfacer de la forma más adecuada las necesidades de la propia conservación. Hay necesidad de una continuidad porque el objeto de los deseos humanos no se satisface gozando una sola vez, sino que necesariamente requiere asegurar de manera permanente la satisfacción del deseo. Como vemos, el concepto de seguridad es clave; seguridad referida a la propia vida, a los bienes, a la propiedad. En efecto, no basta con asegurar la subsistencia en este momento, sino que además se requiere la seguridad de poder conservarla en el futuro. De ahí que los hombres tiendan a acumular todos los bienes que consideran necesarios para asegurar esta conservación de su vida ${ }^{3}$.

Entonces, bien es lo que nos da placer, mal lo que nos da dolor. Placer y dolor inmediatos, placer y dolor lejanos, en cuyo caso se habla de útil o dañino. $O$ sea que bien y mal no son propiedades inherentes a las cosas, o determinables por medio de reglas comunes a todos, sino que derivan de la referencia de las cosas a los deseos y a las repulsiones variables de los individuos.

Para Hobbes, en efecto, la vida psíquica no se desarrolla tan sólo en la dirección del conocimiento, sino también en la de la actividad práctica, y su punto de partida reside en ese mismo movimiento de partículas imperceptibles del organismo animal en el que se ha originado la sensación. Si ese movimiento se transmitiera del cerebro al corazón, él mismo, al favorecer o turbar el "movimiento vital", suscita la tendencia hacia el objeto o la repulsión al mismo, y por consiguiente, placer o dolor. Y como la transformación de la sensación en otros movimientos derivados -hasta la razón-constituye la esfera del conocimiento, así la transformación de la tendencia o repulsión en otros movimientos del alma -hasta la voluntadconstituye la esfera de la vida práctica ${ }^{4}$.

$\mathrm{Y}$ así como es inadmisible la existencia de un bien absoluto, tampoco lo es la de un fin último, de una felicidad que derive de una situación estable que se constituya como la meta definitiva de movimiento y deseo; al cesar el movimiento y el deseo, cesaría también el estado de goce.

${ }^{3}$ Véase Ibid., Parte I, cap. VI, p. 51 y ss.

+ Véase Ibid., Parte I, capítulos I a VI, p. 19 y ss. 
La vida es movimiento perpetuo, y gozar consiste en continuar deseando. De esta forma, se explica el perenne descontento del hombre; nuestra felicidad no consiste en el reposo de un espíritu satisfecho, sino en un continuo pasaje de deseo a deseo, y la conquista de un objeto no es sino camino para la conquista de otro. El bienestar no reposa en "haber estado bien", sino en "estar bien de continuo".

Nuestra alma siempre tiende hacia el futuro, nos dice Hobbes, de allí que anide en todos los hombres un perpetuo e inquieto deseo de poder que sólo cesa con la muerte. Y ello no tanto porque se alimente la esperanza de un placer más intenso que el que se ha alcanzado, o que no pueda conformarse con un poder moderado, sino porque no es posible asegurarse esos poderes y esos medios que se poseen en el presente para vivir bien, más que adquiriendo nuevos poderes y nuevos medios. Esta es la raíz del egoísmo que constituye el fondo genuino de la naturaleza humana; todas las pasiones del hombre se reducen a esta sed egoísta que aspira siempre a mayor poder, incluso las que aparecen eminentemente desinteresadas y altruistas.

De la egoísta naturaleza humana así analizada, Hobbes deriva su doctrina ética. Para él la moral tiende a disciplinar el egoísmo, pero sólo en la medida en que es necesario para la más completa satisfacción del egoísmo mismo. En este sentido, la ética aplica la razón a la naturaleza pasional del hombre, es decir, sustituye el impulso ciego por el cálculo y la previsión. Y como lo que la razón sugiere para esta finalidad no puede ser realizado sino en el Estado, resulta que moral y política se hallan estrechamente unidas. En realidad, la política está en función de la moral, ya que el Estado es condición necesaria para la realización de la ley de la razón. Por otra parte, la moral está en función de la política, en cuanto la voluntad del poder supremo del Estado es la que por sí sola determina lo justo y lo injusto, o sea, lo que en los casos concretos se halla conforme o no con esas leyes que la razón sugiere en vistas del bien entendido egoísmo de los individuos.

Se trata, pues, de "construir" el sistema regulativo de la racionalización del egoísmo; por consiguiente, de construir el Estado con el método deductivo habitual. Dadas las disposiciones del hombre que derivan de su naturaleza psicológica, y debido a las relaciones que los individuos mantienen entre sí por su propia naturaleza, lo mismo que el fin al que se dirige la actividad humana (estado de naturaleza), se busca deducir el sistema de las condiciones más adecuadas para la realización de este fin (estado civil). 
La naturaleza humana es egoísmo, y éste se traduce en aislamiento del individuo, o actitud de hostilidad de uno respecto de los otros; en efecto, cada uno ve en sí mismo su único fin. En consecuencia, lo que empuja al hombre a unirse con los otros hombres en una sociedad estable $y$ rígidamente organizada como es el Estado, no es la benevolencia, sino el temor recíproco de los males inevitables que amenazan continuamente al individuo en el "estado de naturaleza". No por eso puede decirse que los hombres sean malos por naturaleza. En el estado natural no existen lo justo ni lo injusto. La distinción entre lo mío y lo tuyo presupone una ley social y, por ende, un poder común que falta en el estado de naturaleza. "Violencia y engaño" son en ese estado las virtudes cardinales ${ }^{5}$.

\section{De la "guerra de todos contra todos" al Estado}

Como vimos, Hobbes caracteriza al hombre por el egoísmo, y utiliza esta caracterización para justificar una tendencia política: la tendencia a la acumulación ilimitada de bienes.

Asimismo, como para Descartes, para el filósofo inglés la naturaleza ha hecho a los hombres iguales en cuanto a facultades del cuerpo y del espíritu; es decir, son iguales en cuanto a sus poderes naturales para satisfacer la necesidad de su supervivencia. De esta igualdad de poderes entre los hombres, se deriva la igualdad de esperanzas en cuanto a la consecución de los fines. En este sentido, todos los hombres tienen la misma esperanza de asegurar la posesión de las cosas que resulten necesarias para su subsistencia ${ }^{6}$. Ocurre, entonces, que si dos hombres desean la misma cosa y de ninguna manera pueden disfrutarla ambos a la vez, se vuelven enemigos y, finalmente, tratan de aniquilarse o de sojuzgarse el uno al otro en la disputa por la posesión de ese bien que ambos desean. "Si alguien planta, siembra o construye un lugar conveniente, es probable que vengan otros con sus fuerzas unidas para desposeerle y privarle no sólo del fruto de su trabajo, sino también de su vida y de su libertad. Y el invasor, a su vez, se encuentra en el mismo peligro con respecto a otros invasores potenciales"?.

De este texto clásico de Hobbes, se desprende su idea fundamental de la relación que los hombres establecen entre sí en el estado de naturaleza: la guerra de todos contra todos. Es decir que de la igualdad

\footnotetext{
${ }^{5}$ Cf. Hobbes, T., Leviatán, ed. cit., Parte I, cap. XIII, p. 111.

${ }^{6}$ Véase Ibid., p. 108.

${ }^{7}$ Loc. cit., p. 108.
} 
entre los hombres para proveerse de lo necesario para la subsistencia, se sigue, en primer lugar, un estado de desconfianza permanente y mutua entre todos los individuos. Dada esta situación en que cada uno está esperando que otro venga a desposeerlo de sus bienes, incluso con el riesgo de perder la vida en la disputa, sólo existe un procedimiento para que cada hombre se proteja a sí mismo: dominar por medio de la fuerza o de la astucia a todos los otros que puedan querer privarlo de sus bienes o de su vida. Por lo tanto, el estado natural de los hombres es el estado de guerra de todos contra todos.

"Es manifiesto y es evidente que durante el tiempo en que los hombres viven sin un poder común que los atemorice a todos se hallan en la condición o estado que se denomina guerra, una guerra tal que lo es de todos contra todos. Este es el estado natural de los hombres en cuanto individuos naturales"'. Esta guerra, en consecuencia, no sería el resultado de una situación histórica, de una determinada estructura social, política o económica, sino que es la consecuencia necesaria de la naturaleza humana.

Por otra parte, en esta guerra de todos contra todos nada puede ser justo o injusto, como dijimos: "Las nociones de derecho, de legalidad o ilegalidad, de justicia o de injusticia, aquí están totalmente fuera de lugar porque no hay poder común al que todos estén necesariamente sometidos, por lo tanto no hay ley, ni derecho, ni justicia. En el estado de guerra, que es el estado natural de los hombres antes del establecimiento del Estado, la fuerza y el fraude son las dos virtudes cardinales"?.

Sin embargo, los hombres pueden superar el estado de naturaleza, ya que éste les impide el disfrute seguro de los bienes necesarios para la propia vida y la seguridad de la propia conservación, con lo cual, paradójicamente, el hombre se ve imposibilitado de cumplir con el móvil fundamental de su conducta, el objetivo al cual naturalmente tiende. Por eso, los hombres tienden también a superar el estado de naturaleza, porque éste les impide alcanzar su objetivo natural. En consecuencia, el pasaje del estado de naturaleza al estado civil o político no implica un cambio de objetivos; el propósito que los hombres persiguen es siempre el mismo: asegurar la propia vida y los bienes que sean necesarios. Precisamente, el estado civil surge debido a que en el estado de naturaleza el hombre no puede cumplir satisfactoriamente este único objetivo de su conducta.

\footnotetext{
${ }^{8}$ Ibid., p. 109.

${ }^{9}$ Ibid., p. 111.
} 
Hobbes, en este punto, distingue entre derecho natural y ley natural. El primero es la libertad que cada hombre tiene de usar su poder como quiera para la conservación de su propia naturaleza y de sus bienes, planteando una concepción de la libertad como ausencia de cualquier tipo de impedimento o regulación; es la ausencia de toda restricción, la arbitrariedad total. Este derecho natural es el que rige en el estado de guerra de todos contra todos. Pero aparte del derecho natural, existe la ley natural. Esta es un precepto, una regla, o una norma, establecida mediante la razón, en virtud de la cual se prohíbe a los hombres hacer nada que los lleve a destruir su vida o privarla de los medios que le permitan conservarla. El derecho natural es la absoluta libertad que cada uno tiene de hacer lo que considere necesario; pero como este derecho es común a todos los individuos, por este camino, entonces, la libertad de cada uno entra en colisión con la libertad absoluta de los otros, lo cual lleva necesariamente a la guerra de todos contra todos.

La ley natural surge en oposición al derecho natural ${ }^{10}$. En efecto, mientras que el derecho natural es la libertad total, la ley natural es una norma, que somete la conducta a una regulación. Pero el objetivo que persigue la ley natural es el mismo que el que persigue el derecho natural: la conservación de la propia vida y de los propios bienes. Es en virtud de esa ley natural que los hombres llegan a una situación en la que cada uno accede, si los demás también consienten, y mientras se considere necesario para la paz y la defensa de cada uno, a renunciar al derecho natural.

Esta mutua renuncia que se hace en vistas a la seguridad de conservar la propia vida y los propios bienes, se llama contrato ${ }^{11}$, fuente $u$ origen de la justicia. Mientras que en el estado de naturaleza la justicia no existe, ésta va a existir a partir del pacto. La justicia, entonces, no es una virtud natural, no es propia del hombre en cuanto ser natural, ésta no es otra cosa que el cumplimiento de pactos previa y libremente concertados; en este sentido, es algo convencional, artificial, que surge del contrato que los individuos libremente deciden establecer. En consecuencia, antes de la celebración del pacto no hay justicia.

Para que el contrato sea efectivo, se requiere desterrar la desconfianza o el temor que cada uno de los individuos que ha pactado pueda tener respecto de que los demás no cumplan el pacto, desconfianza que se desprende lógicamente dada la descripción que Hobbes ha hecho de

\footnotetext{
${ }^{10}$ Cf. Ibid., Parte I, cap. XIV, p. 113.

${ }^{11}$ Cf. Ibid., p.116.
} 
la naturaleza humana. Es decir, para que el pacto sea efectivo, debe haber seguridad de que todos los contratantes cumplan lo estipulado y respeten el límite que ellos mismos han puesto a su propio derecho. Pero conforme a la concepción de la naturaleza humana que Hobbes ha descripto, los hombres sólo cumplen los pactos si están obligados a ello por un poder coercitivo y superior a todos.

Por otra parte, el pacto no sólo es el origen de la justicia, sino que además da origen a la propiedad privada legítima - no a la posesión de hecho que existe en el estado de naturaleza. En efecto, es solamente en el momento en que cada hombre renuncia a su derecho natural, que adquiere una propiedad sobre determinados bienes, en la medida en que los otros individuos renuncian a sus derechos sobre los mismos. La propiedad, en consecuencia, es tan convencional o tan artificial como la justicia.

En el momento en que los hombres realizan este contrato, surge al mismo tiempo un orden social: la justicia, la legalidad, la propiedad privada, y además se constituye el Estado. "Los pactos que no descansan en la espada no son más que palabras sin fuerza para proteger al hombre. Por consiguiente, si no se ha instituido un poder suficientemente grande para nuestra seguridad, cada uno fiará tan sólo sobre su propia fuerza y maña para protegerse contra los demás hombres", afirma ${ }^{12}$.

$\mathrm{Si}$ en virtud del contrato no surge efectivamente un poder coercitivo capaz de obligar y atemorizar a todos los hombres, éste será letra muerta, por eso "el único camino para erigir semejante poder común capaz de defender a los hombres contra la invasión extranjera y contra las injurias ajenas, asegurándoles así que con su propia actividad y con los frutos de la tierra puedan nutrirse a sí mismos y vivir satisfechos es conferir todo su poder y fortaleza a un hombre o a una asamblea de hombres, todos los cuales, por una pluralidad de votos, puedan reducir su voluntad a una sola voluntad"13. Individuo o asamblea que ejercerá esos poderes en sustitución de cada uno de los individuos que renuncian a hacerlo personalmente en la defensa de su vida. De esta manera, se instituye una unidad real de todos los contratantes, resultado de esta acumulación de los poderes individuales. "Es una sola y misma persona instituida por pacto de cada hombre con los demás, en forma tal como si cada uno dijera a todos los demás: autorizo o transfiero a este hombre o a esta asamblea de hombres mi derecho a gobernarme a mí mismo, con la condición de que todos vosotros

${ }^{12}$ Ibid., Parte II, cap. XVII, p. 148.

13 Ibid., p. 150. 
transferiréis también a él vuestro derecho, y autorizaréis todos sus actos de la misma manera. Hecho esto la multitud así unida en una persona se denomina Estado. Esta es la generación de aquel gran Leviatán, o más bien... de aquel dios mortal, al cual debemos, bajo el Dios inmortal, nuestra paz y nuestra defensa"14.

A partir de esta transferencia del poder y del derecho de cada uno a gobernarse y defenderse a sí mismo, a una persona o a una asamblea, surge una persona jurídica, que es el Estado. Así, el Estado, como la justicia y la propiedad, son artificiales.

Asimismo, el Estado constituye un poder soberano, es decir que no reconoce ningún poder o autoridad que legisle por encima de él. El soberano, además, no puede ser atacado ni depuesto bajo ningún pretexto; por lo tanto, para poder existir y cumplir con todos estos fines, el Estado tiene una sola forma posible: debe ser absoluto. La soberanía del Estado es de tal naturaleza que está por encima de las leyes, de la justicia, de toda legitimidad, en la medida en que la legalidad y la justicia surgen solamente en virtud de un contrato por el cual el individuo deja el estado de naturaleza para pasar a un estado civil o político. Sin embargo, el soberano mismo no está sometido a esas leyes que surgen del contrato, manteniéndose por encima de la legalidad que surge de él, ya que, en realidad, es el soberano la fuente de todo derecho; es el origen de la justicia, del derecho, de la legalidad. "Es inherente a la soberanía el pleno poder de prescribir las normas en virtud de las cuales cada hombre puede saber qué bienes puede disfrutar y qué acciones puede llevar a cabo... Estas normas de propiedad, de lo bueno y de lo malo, de lo legítimo y de lo ilegítimo en las acciones de los súbditos, son leyes civiles y no leyes naturales, son leyes instituidas por el Estado"15. También es el Estado el que elabora las leyes morales.

Siempre que al soberano se le recorta el poder o se le quitan atribuciones, o que se divide ese poder para transferir una parte a otros organismos o sectores de la sociedad, se origina un debilitamiento del Estado. $Y$ desde el momento en que el Estado se debilita, deja de ser ese poder coercitivo superior a todos los individuos y capaz de obligarlos.

Sintéticamente, las causas del mutuo temor son para Hobbes lógicamente deducibles, de: 1) la natural igualdad de los hombres. Cada uno, con su fuerza y con su astucia, puede llegar a matar a otro. La desigualdad actual es fruto de la constitución política de la sociedad. 2) La igualdad del

$1+$ Ibid., p. 150.

15 Ibid., Parte II, cap. XVIII, p.157. 
fin: muchos hombres aspiran a un mismo bien que no puede dividirse ni ser disfrutado en común y por el que, en consecuencia, deben necesariamente entrar en recíproca lucha. 3) Consiguiente desconfianza recíproca y mutua voluntad de dañar, sin límite alguno. 4) Consiguiente derecho de todos sobre todo. Derecho natural es la libertad que tiene cada uno de usar a su arbitrio del propio poder para preservar su vida y de hacer cualquier cosa que le parezca adecuada para este "fin". "Medida del derecho es lo útil". 5) Consiguiente guerra de todos contra todos, característica del estado de naturaleza; hostilidad recíproca, inextinguible a causa de la igualdad de los luchadores.

\section{Protego, ergo obligo, o el cogito ergo sum del Estado}

Schmitt comparte con Hobbes la idea de que en el intercambio entre protección y obediencia radica el fundamento de la obligación política y la garantía de la paz que hace posible la existencia del Estado. Protego, ergo obligo es, como diría Schmitt, el cogito ergo sum del Estado. En su interpretación de Hobbes, Schmitt sugiere que la existencia del Estado podría fundarse en cierta verdad o valor trascendental. Esta verdad o valor, no obstante, sólo puede ser interpretado por el soberano. Lo que interesa, entonces, no es la existencia de una verdad (veritas) que funde el Estado, sino que alguien se halle investido de autoridad (autorictas) suficiente para determinar lo que esa verdad es o significa. ¿Quién interpreta? Sería la pregunta fundamental acerca de los fundamentos normativos del Estado. Schmitt toma esta premisa como tema central de su filosofía política: lo que es verdad para el Estado no es materia de opinión ni puede ser sometido a crítica. Si la obediencia al derecho dependiese de un proceso de discusión racional y argumentación, ello implicaría restaurar el estado de guerra. La ausencia de una autoridad final para determinar lo que es justo e injusto, bien y mal, es para Hobbes el origen mismo de la insoportable anarquía que llevó a los hombres a crear el Leviatán. Dejar en manos del hombre privado el juicio acerca de lo que constituye el bien público, llevaría necesariamente a la disolución del Estado ${ }^{16}$.

${ }^{16}$ Esta es la construcción del sistema hobbesiano expuesta por Schmitt en El concepto de lo politico, en la que la cúspide del sistema se halla abierta al axioma "Jesús es Cristo", el cual debe ser interpretado en el sentido de que el soberano es la única autoridad habilitada para ejercer poder directo dentro del Estado. En la base se halla el individuo que pertenece a un sistema cerrado que Schmitt, en lenguaje hegeliano, 
De ahí que en su Teologia política de 1922, Schmitt intente recuperar para la teoría constitucional moderna el concepto absolutista de soberanía. El concepto de decisión que en el Romanticismo político refería a una actitud personal resuelta, adquiere ahora un claro significado político y legal. En el primer capítulo sobre el concepto de soberanía, Schmitt sostiene que "como todo otro orden, el orden legal se funda en una decisión y no en una norma"17. Esta proposición se dirige contra la teoría normativista de Kelsen. Una de las principales características de esta filosofía es la aceptación del postulado kantiano de que un sistema normativo debe mantener una estricta separación entre el "ser" y el "deber ser". Contra esta teoría, Schmitt señala que el contenido normativo de una prescripción legal sólo puede determinarse por medio de una decisión política. El problema crucial del derecho, para Schmitt, no es la validez de un sistema jurídico sino su eficacia en una situación concreta. A esta conclusión lo conduce la existencia de "estados de excepción" o situaciones de peligro concreto para la vida del Estado. Dado que ninguna norma resulta aplicable a una situación anormal, en el caso de extrema necesidad, el elemento decisional de lo jurídico "se libera de toda atadura normativa y deviene en este sentido absoluto"18. La decisión sobre la excepción, dice Schmitt, "es una decisión en el verdadero sentido de la palabra"1 1 .

El segundo rasgo característico del pensamiento normativista es la reducción del Estado a un puro fenómeno jurídico. Schmitt evoca el concepto de soberano de Bodin como poder absuelto de la ley. El soberano representa el poder de aquél que permanece fuera y por encima de la ley. En tanto el pensamiento constitucionalista liberal busca enmascarar el elemento personal de la soberanía bajo la ficción de que son leyes objetivas y no voluntades humanas las que gobiernan, Schmitt señala que esta ilusión se desvanece ante la emergencia del estado de excepción. El caso crítico destruye la norma revelando que "aquél que decide sobre la excepción" es el soberano dentro del Estado ${ }^{20}$. Según Schmitt, la relación entre soberanía y decisión es típica de lo que él llama una filosofía decisionista del derecho.

llama "sistema de necesidades" (sociedad civil). El individuo se halla excluido tanto de la determinación como de la interpretación de los valores trascendentes del Estado.

${ }^{17}$ Schmitt, Carl, Teología política, Struhart, Buenos Aires, 1985, p. 10.

${ }^{18}$ Ibid., p. 12.

${ }^{19}$ Loc. cit.

${ }^{20}$ Ibid., p. 5. 
El representante clásico de este tipo de pensamiento legal es Thomas Hobbes, como vimos, para quien el derecho-contrariamente a la tradición aristotélico-escolástica- no es ratio (razón) sino voluntas (voluntad). La autonomía del derecho y del poder se sintetiza en la fórmula autorictas non veritas facit legem ${ }^{21}$. El derecho, en otras palabras, debe ser obedecido no por su contenido racional sino por haber sido sancionado por el soberano para establecer la paz y la seguridad.

En su Teología política Schmitt usaba el concepto de "excepción" para atacar la idea de que conflictos extremos pueden ser resueltos por medio de la legalidad o por una deliberación racional. La excepción es el intervalo dramático en el que la legalidad constitucional y la discusión parlamentaria se ven interrumpidas. La decisión sobre la excepción, la "verdadera decisión", revela en un instante la naturaleza dictatorial de la autoridad soberana. Hacia fines de los años 20 , Schmitt retoma la teoría de la excepción intentando ofrecer una definición positiva de su propio concepto de lo político. Lo político, dice Schmitt, "no describe una sustancia propia sino sólo la intensidad de una asociación o disociación de seres humanos cuyos motivos pueden ser religiosos, nacionales (en un sentido cultural o ético), económicos o de otro tipo"22. En otras palabras, no existe tal cosa como una esencia del fenómeno político. Su naturaleza sólo puede ser descubierta en el momento preciso donde una cierta antítesis (de tipo religioso, moral o económico) se transforma en un conflicto de extrema intensidad. Esta, dice Schmitt, se define por la posibilidad de diferenciar entre amigo y enemigo ${ }^{23}$. No es la lucha actual, sin embargo, sino la posibilidad "siempre presente" del combate y de la guerra lo que hace a lo político irreductible a cualquier esfera de acción humana ${ }^{24}$. El enemigo no puede ser reducido a la figura del adversario privado o del competidor económico. Es el que desde dentro (enemigo interno) o desde fuera (enemigo externo) opone y combate en un sentido concreto, vital, la misma existencia de la unidad política ${ }^{25}$. Tampoco se entiende la guerra en este contexto como competición económica o controversia moral o religiosa. El

${ }^{21}$ Esta expresión, frecuentemente citada por Schmitt, resume la filosofía jurídica que Hobbes expone en el capítulo 26 del Leviatán. Véase, Hobbes, Thomas, Leviatán, ed. cit., p. 223.

${ }_{22}$ Véase Schmitt, Carl, El concepto de lo político, ed. cit., p. 38.

${ }^{23}$ Ibid., p. 37.

${ }^{24}$ Ibid., p. 34.

25 Ibid., p. 33. 
término enemigo, al igual que guerra y combate, refieren "a la posibilidad real de exterminio físico"26.

En el surgimiento de un conflicto que reclama distinguir entre amigo y enemigo es donde la teoría decisionista encuentra el concepto de lo político que le es propio. Conflictos extremos son "los que no pueden ser decididos ni por una norma general previamente determinada ni por el juicio desinteresado y, por lo tanto, neutral de un tercero"27. La situación límite llama a una decisión dirigida a preservar la unidad política concreta que se halla amenazada por el enemigo. Esta decisión, sin embargo, no podría ser tomada por cualquier tipo de entidad o asociación. Contra los teóricos del pluralismo social, Schmitt sostiene que el Estado es la única entidad decisiva. Ninguna otra organización posee el derecho de demandar de sus miembros la preparación para morir o matar. Este derecho, por otra parte, es el exacto correlato del supremo deber del Estado de proveer protección y orden ${ }^{28}$. En el caso crítico, el Estado tiene que suspender el derecho tanto para preservar su propia existencia como para crear las condiciones bajo las cuales el derecho puede ser aplicado. Imponer orden y seguridad y, por lo tanto, crear una situación normal, es el prerrequisito de validez de las normas. "Toda norma presupone una situación normal, pues no hay norma que pueda ser válida en una situación enteramente anormal"29.

De la misma forma que lo hizo para arribar a la noción de decisión soberana, Schmitt también juega con diferentes sentidos del término "excepción" para definir el concepto de lo político. Por un lado, la excepción es Ausnabme, significando la noción legal-constitucional de "estado de excepción", el estado de emergencia o peligro extremo. Por otro, Schmitt utiliza excepción como Ernstfall, en el sentido empírico-existencial

\footnotetext{
${ }^{26}$ Ibid., p. 27.

${ }^{27}$ Loc. cit., p. 27.
}

${ }^{28}$ Schmitt retoma aquí su crítica a la penetración de intereses sociales en la esfera política y al ejercicio del poder por entidades privadas carentes de soberanía, como instituciones religiosas, sindicatos e incluso partidos políticos. Estas organizaciones representan para Schmitt la versión moderna de los poderes indirectos que el Estado absolutista del siglo XVII buscó suprimir al obtener el monopolio de la decisión política. El carácter subversivo de estas organizaciones, según Schmitt, yace en el hecho de que demandan lealtad sin estar capacitadas para ofrecer protección. En otras palabras, los poderes indirectos quieren ejercer autoridad sin responsabilidad, quebrando así la ecuación protego, ergo obligo que justifica la obligación política dentro del Estado soberano.

${ }^{29}$ Schmitt, Carl, El concepto de lo político, ed. cit., p. 46. 
del caso crítico o límite. Ambos conceptos, sin embargo, tienen diferentes funciones. Mientras en sentido jurídico, excepción se opone a norma, en sentido empírico, la excepción se opone a lo normal. La razón principal de este uso ambiguo del concepto proviene del propósito de Schmitt de deshacerse del liberalismo político y legal de un solo golpe. La guerra aparece como el caso límite que define lo político y constituye el estado de excepción que llama a una decisión soberana. El problema es que Schmitt carece de argumentos suficientes para probar que sólo la excepción es relevante para comprender la noción de orden legal, o el mismo concepto de lo político.

En la filosofía kantiana del derecho, el derecho de emergencia no es derecho, puesto que el "ser" (la emergencia) debe permanecer estrictamente separado del "deber ser" (el derecho). El caso crítico, por lo tanto, no prueba absolutamente nada porque lo que es excepcional carece de consecuencias jurídicas para un orden legal. Esta proposición puede llevar a un normativismo extremo cuando se utiliza para ocultar que, más allá del sistema legal, la excepción frecuentemente revela dónde reside el poder real dentro de un Estado. Pero Schmitt no sólo quiere conciliar derecho y realidad sino lograr una versión simétricamente opuesta a la fórmula kantiana. Si la guerra -como parece- es lo que Schmitt tiene en mente al hablar de excepción, entonces ésta no es meramente el caso extremo para un orden legal: es su propia negación. Esta es la razón por la cual la excepción no puede utilizarse para definir la naturaleza de la norma. En forma similar, cuando Schmitt define "lo político" por la posibilidad de un conflicto de intensidad extrema, también culmina incluyendo lo excepcional dentro de lo normal sin una razón lógica aparente. Según Schmitt, su concepto de lo político carece de una connotación militarista o belicosa puesto que la guerra no es ni el propósito ni el contenido mismo de lo político. La guerra se concibe más bien como "una posibilidad siempre presente", el presupuesto principal "que determina de una manera característica la acción y el pensamiento humano y crea, por lo tanto, un comportamiento específicamente político ${ }^{30}$. Pero es precisamente como "posibilidad siempre presente" que la noción de excepción pierde todo significado. Si no existe política fuera de la posibilidad de la guerra, entonces ¿a qué regla responde el caso extremo de una excepción?

30 Ibid., p. 34. 
El concepto de lo político en Schmitt se basa en la idea de que la era de la "neutralización y la despolitización" del mundo occidental ha arribado a su fin ${ }^{31}$. De acuerdo con Schmitt, la historia moderna de Europa desde el siglo XVI en adelante puede ser interpretada como una incansable búsqueda por alcanzar una esfera neutral en la que cesaran las luchas y los conflictos. Primero, en el terreno de la moralidad, luego en la competencia económica, y hoy en el proceso de racionalización tecnológica, la cultura occidental se halla comprometida en una utópica búsqueda de armonía que ha asumido la forma de una guerra en contra de la fuente misma de todo mal: el Estado y la esfera de lo político. Esta batalla, declara Schmitt, ha demostrado ser fútil. No sólo no podrían ser suprimidos los conflictos políticos, sino que esos conflictos devienen aún más peligrosos cuando se ocultan detrás de hipócritas razones éticas y económicas. La tecnología, por otra parte, lejos de cumplir su promesa de ser la esfera neutral por excelencia, ha devenido -como probablemente la Primera Guerra Mundial probó a Schmitt- un ciego instrumento al servicio del poder. La búsqueda de una esfera absolutamente neutral donde la humanidad pudiese evadir todo conflicto y encontrar la paz eterna es utópica por la sencilla razón de que, para Schmitt, toda esfera de la existencia humana es potencialmente conflictiva.

\section{El miedo como concepto clave}

En gran parte de su tratado De homine y en los capítulos 1 a 6 de la Primera Parte del Leviatán, como vimos, Hobbes describe las funciones del organismo humano en términos que podrían aplicarse a cualquier animal. Por otra parte, cuando el filósofo alcanza el punto inevitable en el que hay que distinguir entre la naturaleza animal y la humana, hace, en general, caso omiso del tradicional argumento de que el ser humano está dotado de razón a diferencia de las bestias. Hobbes busca otras peculiaridades, y su convicción profunda de que el hombre es un ser fundamentalmente pasional, lo lleva a concebir la razón como consecuencia de otros rasgos, entre ellos el lenguaje.

El origen de la sociedad, entonces, descansa en un ser humano cuyas acciones están guiadas por la tendencia fundamental de satisfacer sus instintos primarios. Para Hobbes, cada hombre es un ser perfectamente

31 Loc. cit. 
independiente de los demás, y el individuo -no las naciones, estados o pueblos- es la unidad primordial de toda especulación social. La sociedad, pues, será la conjugación de un sinnúmero de individuos cuyos instintos básicos son la rapacidad, el deseo de poder, el dominio.

Estando la naturaleza humana dominada por el deseo de competir y obtener gloria, así como por la desconfianza hacia sus congéneres, habrá que suponer, dice Hobbes, que hubo algún tiempo en que, faltando algún poder superior que mantuviera a los hombres en temeroso orden, se encontraran todos ellos en una guerra de todos contra todos. En tales condiciones, según Hobbes, "cada hombre es enemigo de cada hombre ... los hombres viven sin otra seguridad que sus propias fuerzas, y su propia inventiva debe proveerlos de lo necesario. En tal condición no hay lugar para la industria, pues sus productos son inciertos y, por tanto, no se cultiva la tierra, ni se navega, ni se usan mercaderías que puedan importarse por mar, ni hay cómodos edificios, ni instrumentos para mover aquellas cosas que requieren gran fuerza, ni conocimiento de la faz de la tierra, ni medida de tiempo, ni arte ni letras, ni sociedad. Y lo que es peor que nada, hay un constante temor y peligro de muerte violenta; y la vida del hombre es solitaria, pobre, grosera, brutal y mezquina"32.

Hasta Hobbes, las instituciones sociales eran concebidas como expresión de leyes naturales que regían lo social. "La base de la moral y de la política", sin embargo, será ahora "no la ley natural o las obligaciones naturales", sino el "derecho natural". Así podemos reconocer la antítesis entre Hobbes y toda la tradición fundada por Aristóteles y con ella, la decisiva significación de la filosofía política del filósofo inglés. Para éste, el derecho natural debe ser distinguido cuidadosamente de la ley natural, como vimos. El primero se basa en las necesidades del ser humano y es su expresión. El hombre libre ejercita sus derechos naturales, que consisten en alcanzar lo que él considere cosas deseables. Es el derecho soberano de cada individuo, el mismo que regía en el estado de naturaleza, el cual se diferencia de la ley natural que consiste en preceptos alcanzables por medio de la razón; y así como el derecho es la libertad, la ley es la coerción. La sociedad fue fundada mediante un intercambio de derechos realizado voluntariamente. Es decir que los contratos no son otra cosa que un acuerdo entre soberanos acerca de sus derechos. Por eso la justicia, según Hobbes, surge a través de los contratos. Pero aquí volvemos a encontrarnos

32 Hobbes, Thomas, Leviatán, ed. cit., Parte I, cap. XIII, p. 108. 
con una de las ideas claras y constantes de su filosofía, la de fuerza. "Los pactos que no descansan en la espada no son más que palabras sin fuerza" 33 y esa espada no es otra que la del Estado, porque de no existir éste, los pactos no serían duraderos, dadas las características de la psicología humana, sintetizada en la expresión homo homini lupus (el hombre es el lobo del hombre), célebre en su filosofía política.

Entre fines del siglo XVI y comienzos del siglo XVII, es comprensible que la guerra se haya convertido en instrumento de análisis de las relaciones de poder. Hobbes, en este sentido, es el que ha puesto la relación de guerra como fundamento y principio de las relaciones de poder. De hecho para Hobbes, en el fondo del orden, más allá de la paz, por debajo de la ley, en los orígenes de la gran maquinaria constituida por el Estado -el soberano, el Leviatán-, siempre está la guerra: la guerra que se despliega a cada instante y en todas las dimensiones; la guerra de todos contra todos. Hobbes, entonces, no se limita a colocar la guerra de todos contra todos en el origen del Estado -en la aurora real y ficticia del Leviatánsino que la presupone siempre y la ve amenazar y desbocarse incluso después de la constitución del Estado, en los intersticios, en los límites y en las fronteras del Estado.

Recordemos que para Hobbes, aún en un estado civilizado, cuando uno deja el domicilio propio, nunca se olvida de cerrar cuidadosamente la puerta con llave, porque sabe bien que hay una guerra permanente entre los ladrones y los que sufren robos. Además, recuerda que en las selvas americanas hay todavía poblaciones cuyo régimen continúa siendo el de guerra de todos contra todos. Por fin, las relaciones entre un Estado y otro, en Europa, son análogas a las de dos hombres, uno frente al otro, con las espadas desenvainadas y las miradas vueltas la una contra la otra. En todos los casos, entonces, la guerra está presente y constituye una amenaza incluso después de la formación del Estado ${ }^{34}$. Pero una vez constituido el Estado, ¿cuáles son los estigmas de la guerra que permanecen en su cuerpo? ¿En qué consiste la guerra descripta por Hobbes antes y durante la constitución del Estado? ¿Se trata, acaso, de la guerra de los fuertes contra los débiles, de los violentos contra los temerosos, de los valientes contra los cobardes, de los grandes contra los pequeños, de salvajes arrogantes contra tímidos pastores y, finalmente, de una guerra articulada sobre diferencias naturales inmediatas? Está claro que para Hobbes no es

33 Ibid., Parte II, cap. VII.

${ }^{3+}$ Ibid., Parte I, cap. XIII. 
así. La guerra primitiva, la guerra de todos contra todos, es una guerra determinada por la igualdad, nacida de ella, y que se desarrolla dentro de esta igualdad. Es el efecto inmediato de una no-diferencia o, en todo caso, de diferencias insuficientes. De hecho, sostiene Hobbes, si hubiera entre los hombres grandes diferencias, separaciones visibles, manifiestas, claramente irreversibles, la guerra resultaría bloqueada inmediatamente. Si hubiera diferencias naturales marcadas, visibles, masivas, sólo sería posible la siguiente alternativa: o entre el fuerte y el débil hay efectivamente un choque - pero en este caso la guerra real terminaría rápidamente con la victoria definitiva del fuerte sobre el débil-o bien no hay choque efectivo, lo cual significaría simplemente que el débil, consciente de su propia debilidad, desistiría del enfrentamiento. De modo que si hubiera diferencias naturales marcadas no habría guerra: la relación de fuerzas quedaría establecida en su origen por una guerra inicial que excluiría su continuación, o bien, la relación de fuerzas permanecería virtual a causa de la misma vacilación de los débiles.

Por el contrario, ¿qué sucede en el estado de no diferencias o de diferencias insuficientes; en el estado en que hay diferencias serpenteantes, huidizas, minúsculas, inestables, sin orden y sin distinción? ¿Qué sucede en la anarquía de las pequeñas diferencias que caracteriza al estado de naturaleza? Ocurre que incluso el que es un poco más débil que los otros, puede conservarse suficientemente fuerte y no verse forzado a ceder. El débil, entonces, nunca claudica. En cuanto al fuerte, justamente porque se trata de alguien que sólo es un poco más fuerte que los demás, nunca lo es tanto como para no tener que estar en guardia. La indiferenciación natural crea, entonces, incertidumbres, riesgos, casos fortuitos $y$, por ende, la voluntad de parte de unos y de otros de enfrentarse. Lo que crea el estado de guerra es lo aleatorio de la relación de fuerzas original.

En suma, el estado descripto por Hobbes no es exactamente un estado natural y brutal, donde las fuerzas lleguen a enfrentarse siempre directamente; es decir, no estamos en el orden de las relaciones directas entre fuerzas reales. De hecho, en el estado de guerra primitiva, las que se encuentran, se enfrentan y se entrecruzan no son armas, no son fuerzas desencadenadas y salvajes. En la guerra primitiva de Hobbes no hay batallas, no hay sangre, no hay cadáveres. Hay sólo representaciones, manifestaciones, signos, expresiones enfáticas, astutas, mendaces; hay engaños, voluntades disfrazadas de su contrario, inquietudes enmascaradas por certezas. Nos encontramos en el teatro de las representaciones 
intercambiadas, dentro de una relación de miedo que es temporalmente indefinida; pero no estamos realmente en guerra.

En consecuencia, el estado de guerra, según Hobbes, no puede ser caracterizado como un estado de ferocidad bestial, donde los individuos vivientes se devoran entre sí. Más bien, lo que define el estado de guerra es una especie de diplomacia infinita entre rivalidades que están por naturaleza en el mismo nivel. No nos encontramos en la guerra, sino en lo que Hobbes llama, para precisarlo, el estado de guerra. Hobbes afirma que la guerra no consiste sólo en la batalla y en el momento del choque efectivo, sino que se da en un arco de tiempo -es el estado- en el cual la voluntad de enfrentarse en batallas suficientemente manifiesta.

Se comprende, entonces, que ese estado no es una etapa que el hombre abandone definitivamente el día en que el Estado nace, sino que es, en verdad, una especie de fondo permanente que no puede funcionar sin sus astucias elaboradas y sus duplicidades, sin algo que garantice la seguridad, fije la diferencia y coloque, finalmente, la fuerza en una de las partes.

Schmitt, por su parte, compartía con Max Weber la desilusionante conclusión de que el proceso de racionalización del mundo occidental culminó creando una civilización mecanizada y predecible en la que la humanidad se halla hoy atrapada como si se tratase de una jaula de hierro ${ }^{35}$. La teoría decisionista se presentó como la original respuesta que nos permitiría escapar de esa prisión. De la misma manera en que muchos de sus contemporáneos evocaban a Nietzsche en la búsqueda de un hombre nuevo, capaz de afirmar su voluntad e instintos en un mundo petrificado por la técnica, el decisionismo esperaba poner en movimiento una vida política paralizada por ficciones económicas, morales o legales. Schmitt veía en la potencial enemistad y conflicto que caracteriza al fenómeno político la última línea de defensa que evitaría la mecanización total de la vida humana.

35 "El orden económico moderno, decía Max Weber, se halla limitado a las condiciones técnicas y económicas de la producción mecánica que hoy determina la vida de todos los individuos que viven dentro de ese mecanismo, no sólo aquellos preocupados por la adquisición económica, con fuerza irresistible. Quizá así lo determinará hasta que la última tonelada de carbón sea quemada. De acuerdo con Baxter, el cuidado por los bienes externos sólo debería posarse sobre los hombros del santo como si se tratase de un abrigo liviano que puede ser arrojado a un costado en cualquier momento. Pero el destino quiso que ese abrigo se convirtiese en una jaula de hierro". (Weber, Max, La ética protestante y el espiritu del capitalismo, Alianza, Madrid, 1987, p. 181). 
La guerra, para Schmitt, representa la más alta expresión de la actividad humana y la negación más radical de los valores esenciales del mundo burgués: seguridad, utilidad y racionalidad. Sólo rescatando lo político y, por lo tanto, la guerra, sería finalmente posible desprenderse de los valores que crearon una civilización vacía y opresiva.

Asimismo, Schmitt parece estar aún más obsesionado que Hobbes por justificar la existencia de una esfera de decisión absolutamente indiscutible. En primer lugar, Hobbes, como vimos, es un teórico contractualista. Esto implica que para Hobbes, en último análisis, la misma creación del Estado, depende de una decisión del individuo ${ }^{36}$. Por otra parte, Hobbes admite también la existencia de una esfera de conciencia individual ("fe" privada como opuesta a "confesión" pública) que es libre respecto de los dictados de la autoridad. Tanto en el contractualismo como en la esfera de conciencia individual, Schmitt ve un potencial desafío a la autoridad soberana $y$, en ello, una puerta abierta a la futura restauración de la guerra. En tanto para Hobbes, el Estado pone fin a la guerra de todos contra todos del estado de naturaleza, Schmitt hace de la guerra una amenaza permanente para la autoridad del Estado. En términos jurídicos, esto significa que la relación entre decisión soberana y excepción también se halla invertida. En Hobbes, el estado de guerra -la excepción por excelencia- es parte de una existencia prepolítica y, por lo tanto, prejurídica. Para Schmitt, por el contrario, la excepción, siendo diferente de la anarquía o el caos, "permanece dentro del esquema de lo jurídico"37. En otras palabras, Schmitt incorpora la excepción dentro del orden político y legal. De la misma manera en que para el normativista la excepción nada prueba dentro de un orden legal, Schmitt busca demostrar que la excepción, no la norma, revela la naturaleza real del derecho. Lo que generalmente ocurre carece de interés. "La regla, dice Schmitt, nada prueba; la excepción todo: confirma no sólo la regla sino también su existencia, la cual sólo deriva de la excepción"38. Los costos de esta fórmula son muy altos: si lo excepcional se convierte en normal y si la norma sólo puede vivir de la excepción, significa que para que

\footnotetext{
36 Hobbes, Thomas, Leviatán, ed. cit., cap. XXIX, p. 297.

37 Schmitt, Carl, Teología política, ed. cit, 1985, p. 13.

38 Ibid., p. 15.
} 
el Estado sobreviva, su autoridad debe adquirir la estructura de una dictadura permanente ${ }^{39}$.

En consecuencia, la crítica de Carl Schmitt al liberalismo puede resumirse en el concepto del decisionismo. En su visión, decisionismo significa lo opuesto al pensamiento normativista y a una concepción de la política basada en el ideal de la discusión racional. Como doctrina legal, el decisionismo sostiene que en circunstancias críticas la realización del derecho depende de una decisión política vacía de contenido normativo. Desde una perspectiva ético-política, sin embargo, la esencia del decisionismo no implica la ausencia de valores y normas en la vida política sino la convicción de que éstos no pueden ser seleccionados por medio de un proceso de deliberación racional entre visiones alternativas del mundo. Valores y normas deben ser interpretados y decididos por quien detenta el poder. En su dimensión filosófica, el decisionismo de Schmitt es una reacción contra los principios de la crítica, heredados del Iluminismo.

\section{Voluntad-miedo-soberanía}

Hobbes distingue dos categorías de soberanía: la de institución y la de adquisición. Con respecto a la primera, algunos hombres tomarán decisiones que no son tanto las de transferir a alguno -o a muchos- una parte de sus derechos y de su poder, o de delegar todos sus derechos, sino más bien las de conceder a alguno-que puede incluso estar compuesto por muchos y ser así una asamblea- el derecho de representarlos total e integralmente. No se trata de una relación de cesión o de delegación de algo que pertenece a los individuos, sino de una representación de los individuos mismos.

Esto significa que el soberano así constituido sustituirá integralmente a los individuos. No será simplemente depositario de una parte de sus derechos, sino que estará efectivamente en el lugar de ellos, asumiendo la totalidad de su poder. Como dice Hobbes, la soberanía constituida de ese modo asume la personalidad de todos. Los individuos así representados estarán presentes en su representante y cada cosa que haga el soberano será como una cosa hecha por cada uno de ellos. En tanto representante de los individuos, el soberano estará modelado exactamente

${ }^{39}$ Esta es la consecuencia última que, según Schmitt, debería derivarse de la teoría hobbesiana del Estado. Véase Schmitt, Carl, La dictadura, Alianza, Madrid, 1985, p. 54. 
en base a ellos. Es, por lo tanto, una individualidad fabricada, pero no por ello menos real, tanto en el caso de que el soberano sea un monarca individual, como en el que se trate de una asamblea. Las repúblicas de institución constituyen un mecanismo donde sólo existe el juego de las voluntades, del pacto y de la representación ${ }^{41}$.

Por su parte, en el caso de la otra forma de constitución de las repúblicas, parecería que nos enfrentamos con una soberanía que se funda sobre relaciones de fuerza reales, históricas, inmediatas. Es necesario, frente a esta forma, suponer no tanto un estado primitivo de guerra sino, más bien, una batalla históricamente determinada ${ }^{41}$.

Consideremos como ejemplo un Estado constituido sobre la base del modelo de la institución y supongamos que sea atacado con las armas por otro Estado. Es vencido, su ejército derrotado y disperso, su soberanía destruida, sus tierras ocupadas por el enemigo. Nos encontramos aquí frente a una verdadera guerra, con batallas donde se miden las relaciones de fuerzas. Hay, finalmente, vencedores y vencidos; vencidos que están a merced de los vencedores.

Que los vencidos estén a merced de los vencedores, significa que éstos pueden matar a los primeros. En este caso, la soberanía del Estado desaparece porque los individuos de este Estado desaparecieron. Pero si los vencedores dejan con vida a los vencidos, éstos, entonces, teniendo el beneficio provisorio de la vida, no tendrán alternativas: o se sublevan contra los vencedores, reanudando efectivamente la guerra, intentando, así, invertir la relación de fuerzas y arriesgándose a morir, o bien aceptan obedecer, trabajando para los otros, cediendo la tierra a los vencedores y pagándoles tributos. En el primer caso volvemos a encontrarnos con la guerra real, que la derrota había suspendido provisoriamente. En el segundo, se dará lugar a una relación de dominación enteramente fundada sobre la guerra y sobre la prolongación, en la paz, de los efectos de la guerra.

$\mathrm{Y}$ en este caso, Hobbes nos dice que aún nos hallamos dentro de una relación de soberanía, puesto que a partir del momento en que los vencidos eligieron la vida y la obediencia, han reconstituido una soberanía, han transformado a los vencedores en sus propios representantes, restaurando un soberano en el lugar del que fue vencido en la guerra. No es entonces la derrota - de manera brutal y fuera del derecho- la que funda una sociedad de dominación, de esclavitud, de servidumbre, sino que el nuevo

to Hobbes, Thomas, Leviatán, ed. cit., Parte II, cap. XVIII, p. 153 y ss.

${ }^{+1}$ Ibid., p. 174. 
Estado se crea después de la batalla, luego de la derrota militar y, en cierto modo, independientemente de ella. Lo que hace entrar en el orden de la soberanía y en el régimen jurídico del poder absoluto, es el miedo, la renuncia al riesgo de perder la vida. La voluntad de elegir la vida más que a la muerte funda una soberanía que está basada jurídicamente y es legítima, tanto como aquella que se constituye sobre la base de la institución y del acuerdo recíproco.

Por último, Hobbes agrega una tercera forma de soberanía que es muy similar a la de adquisición, aquella que, como vimos precedentemente, aparece en el crepúsculo de la guerra y después de la derrota. Este tipo ulterior de soberanía, dice Hobbes, es análogo al que liga a un niño a sus padres, o más exactamente a su madre ${ }^{42}$. Cuando un niño viene al mundo sus padres tienen no sólo el poder de dejarlo morir sino también el de hacerlo morir. El niño no puede vivir sin los progenitores, y por muchos años, espontáneamente, sin que deba expresar de otro modo su propia voluntad -sólo a través de la manifestación de las propias necesidades (gritos, llantos, miedos)-, el niño obedecerá a los padres, a la propia madre, y hará exactamente lo que ella le ordene, ya que de ella depende su vida. La madre, entonces, ejercerá sobre él la propia soberanía.

Entre el consenso del niño -consenso que ni siquiera pasa a través de una voluntad expresa o de un contrato- a la soberanía de la madre a fin de conservar la vida, y el consenso de los vencidos en el crepúsculo de la derrota, no hay diferencias sustanciales. De hecho, Hobbes entiende que está mostrando que en la constitución de la soberanía no son ni la cualidad de la voluntad ni su forma de expresión, o su nivel, las que resultan decisivas. En el fondo, poco importa que se tenga un cuchillo en la garganta o que se pueda expresar o no explícitamente la voluntad propia. Para que haya soberanía, en realidad, es necesario y suficiente que esté efectivamente presente aquella voluntad que hace que se quiera vivir incluso cuando eso no fuera posible sin la voluntad de otro. La soberanía se constituye, entonces, a partir de aquella forma radical de voluntad que está ligada al miedo $-\mathrm{y}$ no desde arriba, es decir por la fuerza de una decisión del más fuerte, del vencedor (o de los padres). La soberanía se forma siempre desde abajo, a través de la voluntad de quienes tienen temor. De modo que a pesar de la ruptura que puede aparecer entre las dos grandes formas de república (la de institución, nacida de la relación recíproca, y la de adquisición, nacida

\$2 Ibid., p. 173. 
de la batalla), entre una y otra emerge una profunda identidad en el mecanismo de funcionamiento. Trátese de un acuerdo o de una batalla, o de una relación como la de padres e hijos, encontramos siempre la misma serie: voluntad-miedo-soberanía.

En el fondo, lejos de ser el teórico de las relaciones entre la guerra y el poder político, parecería que Hobbes quiere eliminar la guerra en tanto realidad histórica. En el Leviatán hallamos un discurso que afirma que poco importa haber perdido o no; poco importa haber sido o no derrotados, puesto que en todos los casos, es siempre el mismo mecanismo el que funciona para los vencidos, mecanismo que se encuentra en el estado de naturaleza, en la constitución del Estado e incluso en la relación más tierna y natural que existe, vale decir en la que se da entre los padres y sus hijos. Hobbes transforma la guerra, el evento bélico, la relación de fuerzas que se ha manifestado efectivamente en la batalla, en algo diferente para la constitución de la soberanía; en efecto, ésta ignora la guerra. Y en todos los casos, haya o no guerra, se realiza siempre del mismo modo. El discurso de Hobbes es, en el fondo, un no a la guerra, y en esto se diferencia notoriamente de Schmitt.

En este sentido, Hobbes mantiene siempre el discurso del contrato y de la soberanía, porque, en realidad, el adversario invisible del Leviatán era la utilización política, en las luchas de la época, de un determinado saber histórico relativo a las guerras, a las invasiones, a los saqueos, a las desposesiones, a las confiscaciones, a las rapiñas, a las extorsiones. En suma, un saber histórico relativo a los efectos de los comportamientos de la guerra, de las acciones militares y de las luchas reales en las leyes y en las instituciones que aparentemente regulan el poder. En síntesis, parecería que lo que Hobbes quiere eliminar es la conquista o la utilización del discurso sobre la conquista en el discurso histórico y en la práctica política.

Por el contrario, Schmitt se refiere a otro tipo de soberanía. Quizá la mejor analogía para describir el tipo de autoridad soberana que Schmitt tiene en mente es la de un dios creador. Esta imagen se inspira en el diputado y líder reaccionario español Donoso Cortés, quien en 1849 propuso que sólo una dictadura católica podría salvar a Europa del mal encarnado en la entonces creciente amenaza socialista. Schmitt también tomó de Cortés la idea de que la “excepción en jurisprudencia es análoga al 
milagro en teología"43. En esta concepción, el rechazo que hace el Estado liberal de la excepción, tiene correlato en una cosmología deísta que ha eliminado el milagro de este mundo. De la misma manera, tal como Dios fue expulsado de la historia por el Iluminismo, reduciendo la realidad del mundo al mecánico funcionamiento de leyes naturales, así el liberalismo erradicó la intervención dictatorial del soberano del escenario constitucional, disfrazando el mando personal tras la abstracción de un "gobierno de las leyes". Sin embargo, a diferencia de Donoso Cortés, Schmitt no esta tan interesado en traer el reino de Dios a la esfera de lo político como en hacer del soberano un dios secularizado. "Mirado desde un punto de vista normativo, dice Schmitt, la decisión emana de la nada"44. La decisión es como un acto del Dios creador: proviene del caos para crear un orden por voluntad divina.

Pero, ¿por qué es el conflicto político (y, en última instancia, la guerra) inevitable? Detrás de su aparente neutralidad valorativa, le es difícil a Schmitt ocultar su juicio moral acerca de la necesaria relación entre guerra, política y naturaleza humana. Schmitt ha asumido que la única manera de comprender seriamente el fenómeno político es admitir la maldad inherente a la naturaleza humana ${ }^{45}$. Si la esfera de lo político se halla en última instancia condicionada por la posibilidad de enemistad, entonces, "las ideas y concepciones políticas no pueden comenzar muy bien con un optimismo antropológico"46. Este es, a su juicio, el principal error del liberalismo, anarquismo y comunismo: todos niegan el hecho de que el hombre es un ser "malo" o, al menos, "peligroso". A diferencia de las otras ideologías, sin embargo, el liberalismo es quien en particular olvida la distinción entre amigo y enemigo, renunciando a tomar partido en la lucha política. El sueño utópico del liberalismo sería un mundo donde los conflictos políticos se vieran transformados en controversias morales $o$ en competencia económica. Un mundo tal, piensa Schmitt, sería completamente inhumano. Un mundo en el que la posibilidad de la guerra fuese eliminada, sería contrario a la vida, un oscuro lugar falto de antítesis "significativas" e "interesantes" que pudieran requerir de los hombres "sacrificar su vida,

\footnotetext{
+3 Schmitt, Carl, Teología política, ed. cit., p. 32.

+t Ibid., pp. 31-32.

${ }^{45}$ Lo mismo que para Hobbes, el pesimismo antropológico es, en última instancia, la fundamentación de la teoría del Estado en Carl Schmitt. ${ }^{46}$ Schmitt, Carl, El concepto de lo politico, ed. cit., p. 64.
} 
verter sangre o matar a otros seres humanos"47. En otras palabras, un mundo poblado de máquinas carentes de emoción. Pero si ésta es la imagen escalofriante de un mundo apolítico, debemos preguntarnos por qué un mundo en el que los seres humanos se hallaran alienados de toda decisión moral relevante para la vida política sería un mundo más humano. Después de todo, un hombre dispuesto a luchar sólo cuando se lo ordena la autoridad no difiere demasiado de un autómata.

Por último, las relaciones de poder de una sociedad se injertan esencialmente en una relación de fuerzas establecida en un determinado momento, el momento históricamente precisable, de la guerra. $\mathrm{Y}$ si es verdad que el poder político detiene la guerra, haciendo reinar la paz en la sociedad civil, no es para suspender los efectos de la guerra o para neutralizar el desequilibrio que se manifestó en la batalla final. El poder político, en esta hipótesis, tiene de hecho el rol de inscribir perpetuamente, a través de una especie de guerra silenciosa, la relación de fuerzas en las instituciones, en las desigualdades económicas, en el lenguaje, etc. La política sería, así, la sanción y el mantenimiento del desequilibrio de las fuerzas que se manifestaron en la guerra.

Asimismo, dentro de la paz civil, o sea en un sistema político, las luchas políticas, los enfrentamientos relativos al poder, con el poder o para el poder, las modificaciones de las relaciones de fuerza (con las relativas consolidaciones y fortalecimientos de las partes), deberían ser interpretados sólo como la continuación de la guerra. Serían, así, descifrados como episodios, fragmentaciones, cambios de lugar de la guerra misma y, de este modo, aunque se escribiera la historia de la paz y de sus instituciones, no se escribiría otra cosa que la historia de la guerra.

Pero, paradojalmente, tras el argumento de Schmitt, la decisión definitiva sólo puede venir de la guerra, es decir de una prueba de fuerzas en la cual, finalmente, sólo las armas deberán ser los jueces. La última batalla sería el fin de la política. Sólo la última batalla suspendería el ejercicio del poder como guerra continua.

\section{Bibliografía}

Dotti, Jorge. E., "El Hobbes de Schmitt", en Cuadernos de Filosofía, 32, Buenos Aires, 1989, pp. 57-71.

${ }^{47}$ Ibid., p. 35. 
Hobbes, Thomas, Leviatán, Editorial UPR, Puerto Rico, 1978.

Schmitt, Carl, Teología política, Struhart, Buenos Aires, 1985.

Schmitt, Carl, El concepto de lo político, Folios, Buenos Aires, 1984.

Schmitt, Carl, La dictadura, Alianza, Madrid, 1985.

Schmitt, Carl, Romaticismo político, Struhart; Buenos Aires, 1985.

Schmitt, Carl, El Leviathan en la Teoría del Estado de Thomas Hobbes, Struhart, Buenos Aires, 1990.

Weber, Max, La ética protestante y el espiritu del capitalismo, Alianza, Madrid, 1987.

\section{Resumen}

Para Hobbes, la naturaleza humana es egoísmo, y éste se traduce en aislamiento del individuo, o actitud de hostilidad de uno respecto de los otros -la "guerra de todo contra todos"-; en efecto, cada uno ve en sí mismo su único fin. En consecuencia, lo que empuja al hombre a unirse con los otros hombres en una sociedad estable y rígidamente organizada como es el Estado, no es la benevolencia, sino el temor recíproco de los males inevitables que amenazan continuamente al individuo en el "estado de naturaleza". No por eso puede decirse que los hombres sean malos por naturaleza. En el estado natural no existen lo justo ni lo injusto. La distinción entre lo mío y lo tuyo presupone una ley social y, por ende, un poder común que falta en el estado de naturaleza. "Violencia y engaño" son en ese estado las virtudes cardinales.

También para Schmitt, el conflicto político y, en última instancia, la guerra, es inevitable, ya que detrás de su aparente neutralidad valorativa, no puede ocultar su juicio moral acerca de la necesaria relación entre guerra, política y naturaleza humana. Schmitt ha asumido que la única manera de comprender seriamente el fenómeno político es admitir la maldad inherente a la naturaleza humana. Si la esfera de lo político se halla en última instancia condicionada por la posibilidad de enemistad, entonces, "las ideas y concepciones políticas no pueden comenzar muy bien con un optimismo antropológico". Este es, a su juicio, el principal error del liberalismo, anarquismo y comunismo: todos niegan el hecho de que el hombre es un ser "malo" o, al menos, "peligroso".

En consecuencia, lo mismo que para Hobbes, el pesimismo antropológico es, en última instancia, la fundamentación de la teoría del Estado en Carl Schmitt. 


\begin{abstract}
For Hobbes, the human nature is selfishness, and this is translated in individual isolation, or hostile attitude -"war of everything against all"- in effect, each one sees in himself his only purpose. In consequence, what pushes the man to join with other men in a stable and rigidly organized society as the State is, it is not the benevolence, but the reciprocal fear of the inevitable evil that constantly threaten the individual in his "natural state". Not because of this we can say that the men are evil in nature. In the natural state, justice and injustice do not exist. The distinction between mine and yours, presupposes a social law and consequently, a common power that lacks in the state of nature. "Tiolence and fraud" are, in this state, the cardinal virtues.

For Schmitt, the political conflict and, in last instance the war, is also inevitable, since behind its apparent valorative neutrality, it cannot hide its moral judgment about the necessary relation among war, politics and human nature. Schmitt has assumed that the only way of comprehending seriously the political phenomenon is to admit the evilness inherent to the human nature. If the sphere of the political is determined, in last instance, by the possibility of hatred, then, "the ideas and political conceptions cannot begin very well with an anthropologic optimism". For Schmitt the principal mistake of the liberalism, anarchism and communism is: they all deny the fact that the man is "evil" or, at least, "dangerous". In consequence, the same as for Hobbes, the anthropologic pessimism is in Carl Schmitt the foundation of the theory of the State.
\end{abstract}

